\title{
Evolución y desarrollo de la arquitectura en Santiago de Veraguas, desde el siglo XVI hasta el siglo XXI.
}

\section{Sebastián Ariel Aguilar Medina ${ }^{1 *}$}

${ }^{1}$ Departamento de Arte, Facultad de Arquitectura y Diseño, Centro Regional Universitario de Veraguas, Universidad de Panamá.

*Autor para Correspondencia. E-mail: arq.sebastianaguilar@yahoo.com

\section{Resumen}

Este artículo se desprende de la investigación denominada Evolución Arquitectónica y Urbana, de la ciudad de Santiago de Veraguas, desde la época Colonial (Siglo XVII), hasta la fecha, haciendo énfasis en la parte técnica, el diseño arquitectónico y la planificación urbana. El objetivo de esta investigación es ofrecer un trabajo teórico-dinámico, que integre la metodología de la investigación arquitectónica y la información historiográfica. Los resultados obtenidos pueden ser utilizada como material con base didáctica y técnica en futuras investigaciones de profesionales, estudiantes y para el uso cultural de toda la población panameña y a nivel internacional. Aquí se tocan aspectos, como los sistemas constructivos utilizados y sus pasos detallados, utilización de materiales y su procedencia, crecimiento poblacional y análisis de la misma, influencia de la población en el desarrollo urbano de las áreas estudiadas, fecha y construcción de edificaciones, estilos arquitectónicos, infraestructuras desde su creación a posibles proyecciones, desarrollo de planos y reconstrucción de algunas edificaciones. En esta investigación se analizaron una extensa documentación gráfica, por medio de diseños, fotografías, planos inéditos, teorías de desarrollo urbano, que fueron de gran ayuda para conocer la evolución de la ciudad y sus futuras proyecciones.

Palabras clave: Santiago, Veraguas, Arquitectura, Urbanismo, Patrimonio Arquitectónico, Colonial, Siglo XIX, Plaza, Calles, Central, Fundación.

\footnotetext{
Abstract

This article is derived from the research called Architectural and Urban Evolution, from the city of Santiago de Veraguas, from the Colonial period (XVII Century), to date, with emphasis on the technical part, architectural design and urban planning. The objective of this research offers a theoretical-dynamic work that integrates the methodology of architectural research and historiographic information. The results obtained can be used as material with didactic and technical
} 
basis in future research of professionals, students and for the cultural use of the entire Panamanian population and internationally. The aspects are touched, such as the construction systems used and their detailed steps, use of materials and their origin, population growth and analysis influence of the population in the urban development of the areas studied, date and construction of buildings, styles architectural, infrastructures from its creation tor possible projections, development of plans and reconstruction of some buildings. In this research an extensive graphic documentation was analyzed, through designs, photographs, unpublished plans, urban development theories, which was very helpful to know the evolution of the city and future projections.

Kaywords: Santiago, Veraguas, Architecture, Urbanism, Architectural Heritage, Colonial, 19th Century, Plaza, Streets, Central, Foundation.

\section{Introducción}

Se realizó una investigación exhaustiva sobre la ciudad de Santiago de Veraguas, desde sus inicios, las teorías de su fundación, analizadas e investigadas por diferentes historiadores y científicos, su creación como ciudad, la procedencia del nombre de la ciudad y el título de ciudad de la misma.

En la ciudad de Santiago de Veraguas existen escasas investigaciones especializadas en arquitectura y urbanismo. Siendo así, surge la necesidad de ampliar estudios sobre el tema en esta ciudad, con la idea de generar una visión más amplia, en términos historiográficos, de la realidad arquitectónica de Santiago.

De esta investigación se analizan temas específicos como la falta de planificación urbana en el crecimiento de la ciudad, la evolución y avance en el tema arquitectónico y ejemplos de planificación urbana. También se profundiza las tendencias y causas, que han hecho crecer la ciudad de una forma desorganizada y el resultado de su fisionomía actual.

Se detallan y organizan, todos los periodos de desarrollo de la ciudad de Santiago de Veraguas, su crecimiento, fisionomía en diferentes periodos, avances, problemáticas, sistemas constructivos, tendencias, limitaciones, y todos los elementos que integran esta ciudad físicamente desde sus fundaciones hasta la fecha, todo analizado desde el punto de vista urbano y arquitectónico.

Uno de los puntos investigados y analizados profundamente es la problemática que encontramos en nuestra ciudad desde el punto de vista urbano, el cual es, la falta de planificación técnica de la misma, nuestra ciudad ha sido formada y desarrollada, de manera espontánea, basándose en causas sociales, no ha sido planificada desde sus inicios y hoy en día presenta grandes problemas vinculadas a las actividades actuales de nuestra sociedad y sus niveles de vida y cambios de tecnología.

Otro problema palpable es la falta de conservación de las edificaciones patrimoniales de la ciudad, producto resultante de un proceso de deterioro acumulado en el tiempo y transformaciones provocadas por la adaptación a nuevos usos, por divisiones o ampliaciones de las obras sin consulta especializada, y por la influencia "modernizadora" de la arquitectura de los últimos años en la ciudad de Santiago; lo que provoca la pérdida de los valores, y, por ende, la autenticidad de las obras. 
Se describe de manera detallada algunos edificios según sus tipos, ya sea residenciales, comerciales, religiosos y de tipo público. Esta información acompañada de los medios de comunicación existentes en la época, el acceso a la ciudad, su comunicación con otros poblados, la creación de las Plazas y sus calles. Además, hacemos una descripción de los sistemas de transporte, iluminación, abastecimiento de agua y demás facilidades con que se contó en cada periodo de la ciudad.

Para ver de manera más clara la arquitectura y desarrollo urbano de la ciudad la hemos dividido cronológicamente en 5 épocas específicas: la primera, Época Colonial Siglo XVII y Siglo XVIII (Génesis de Santiago), la segunda, el periodo que abarca el final de la Época Colonial y la Unión de Panamá a Colombia (Siglo XIX) (Primera Expansión Urbana), la tercera etapa cubre el principio de Siglo XX (de 1900 a 1949) (Santiago La Pintoresca); la cuarta etapa es la Segunda mitad del Siglo XX (1950-1999) (Revolución Moderna y Urbana) y la quinta y última etapa cronológica el Siglo XXI (del 2000 a la fecha 2016) (inicio del Vanguardismo Arquitectónico y Segunda Expansión Urbana).

\section{Materiales y métodos}

La presente investigación se fundamentó mediante el trabajo de campo, la revisión de fuentes bibliográficas y documentación en archivos. Se emplearon métodos teóricos: histórico-lógico, sistémico-estructural y análisis-síntesis; y el método empírico: observación de la realidad.

Se analizaron variables de otras ramas, aparte de la arquitectura y planeamiento urbano, que apoyaron esta investigación, para identificar el problema tratado. La metodología y las variables de estudio, se definieron, para caracterizar de la arquitectura histórico urbana de Santiago de Veraguas, objetivo principal de la investigación, partió de un análisis integral que contempló el marco histórico en que surge y se desarrolla la arquitectura y urbanismo en el contexto nacional y local, el estudio de los

referentes historiográficos relacionados con el tema, los aspectos de carácter teórico-metodológico (las metodologías de análisis de la arquitectura), los criterios sobre estudios tipológicos y las aportaciones del medio geográfico en que se enclava el objeto de estudio.

Se utilizaron métodos tradicionales de vanguardia como:

- Incorporación del uso de aplicaciones informáticas y herramientas en línea que permitieron automatizar procesos tediosos de búsqueda y gestión bibliográfica.

- Revisión crítica, de artículos de investigación y lecturas existentes.

- Encuestas a residentes de estas áreas, instituciones estatales y demás.

- Revisión de estadísticas existentes y aplicándolas al problema en investigación.

- Utilización de métodos gráficos para resultados de los datos.

- Trabajo analítico con el estudio de los planos y mapas desde inicios de la fundación de la ciudad hasta la fecha.

- Revisión de aspectos metodológicos de proyectos ya realizados dentro del área o en otras ramas.

Revisión de publicaciones donde suelen difundirse los resultados de investigación y la producción académica o artística de los profesionales del área. 
En la bibliografía consultada, hemos encontrado, algunos temas como la definición del período general de desarrollo, así como etapas evolutivas vinculadas a los factores de orden socioeconómico y cultural en cada contexto, diversidad de temas arquitectónicos (Fabian Garré, 2001), (Puente San Millán, 2014). Asimilación de códigos por las distintas clases sociales, relacionados con las tipologías constructivas llevadas a cabo, tanto por profesionales como por constructores y usuarios.

Se realizaron el análisis de las obras en el orden de lo formal, y en menor medida de lo técnicoconstructivo y lo funcional. En estos estudios formales se menciona la volumetría ceñida a los planos de fachada, y definida en este caso por los elementos decorativos a relieve. Los patrones estéticos de la arquitectura tienen incidencia directa y transforman esencialmente la expresión formal, reflejada tanto en interiores como en exteriores.

Todas estas fuentes (libros, revistas científicas, periódicos, informes técnicos y de investigación de instituciones públicas y normas técnicas.) fueron dirigidas directamente a extraer información sobre la evolución, fundación, crecimiento y características de la ciudad de Santiago de Veraguas, limitándonos en las áreas de estudio del urbanismo y la arquitectura. Utilizamos un patrón de análisis para los datos cuantitativos o cualitativos que demandó la integración de aspectos que provienen, en parte, de la extensa literatura disponible en el ámbito de la investigación y la estadística (Grout, 2010), (Francesc Caballé I Esteve, 2003). Otra parte proviene de la experiencia que acumulamos en el campo de trabajo y la frecuencia con que realiza este tipo de labor.

Tomamos en consideración los elementos decorativos, las terminaciones, la herrería, elementos componentes como pilastras adosadas, la carpintería y la forma del remate; y en los interiores: los pisos, la iluminación, el color, el revestimiento de los muros, el diseño de las escaleras y la ornamentación. Lo referido anteriormente se muestra compatible con las metodologías empleadas en otros análisis tipológicos, tanto teóricos como aplicados específicamente a un caso de estudio. Destacamos el estrecho vínculo entre los estilos y el medio geográfico, lo que puede generar estilos y tipologías regionales.

Otra metodología planteada de forma general que el análisis se dirigió hacia la comprensión global de los fenómenos arquitectónicos, considerados como un todo coherente, donde deben concebirse los sistemas arquitectónicos y urbanos en su desarrollo histórico concreto, ubicado en tiempo y espacio y condicionados por los diversos factores que caracterizan la sociedad y el contexto físico en el cual se insertan (Puente San Millán, 2014). De esta forma, se trazó una estructura flexible que parte de considerar los factores socioculturales y socioeconómicos definidos por el contexto espacio-temporal donde se generó la obra, hasta determinar su significación cultural y su apreciación dentro de la cultura arquitectónica. Para ello se valió de leyes y principios dictados por el materialismo histórico y dialéctico, ellos son: el principio de los sistemas, el principio de los factores condicionantes, el principio del proceso de diseño, el principio de la significación, y el principio de la relación en arquitectura entre el pensamiento lógico-científico y el estructurado en imágenes (Puente San Millán, 2014).

Se tomó en cuenta paralelamente la singularidad aportada por la geografía del sitio; entiéndase la incidencia de la topografía de la ciudad en las edificaciones; la ubicación del asentamiento sobre fallas tectónicas de considerable importancia y su efecto en la conformación de la arquitectura; por último, 
el estilo arquitectónico impreso en la ciudad y sus habitantes, y su relación con las propuestas arquitectónicas.

Durante la investigación se definieron tres grupos funcionales:

a) Edificios públicos.

b) Edificios de vivienda.

c) Edificios Religiosos.

Una vez que se determinaron estos grupos funcionales se realizó el estudio a partir de dos variables:

1. El análisis del emplazamiento urbano de las obras, que se acometió para el sector de manera general.

2. La solución formal y expresividad arquitectónica de las fachadas y los ambientes interiores principales de las edificaciones.

Referido al análisis de fachada se considerarán las siguientes subvariables:

1.- Tipo de fachada

2.- Relaciones de la fachada: composición, proporción y predominio.

3.- Textura de la superficie de fachada.

4.- Elementos decorativos de la fachada.

Referido al análisis de los ambientes interiores principales fueron consideradas las siguientes subvariables:

1.- Presencia y diseño de elementos divisorios entre crujías.

2.- Presencia de elementos decorativos en interiores.

3.- Diseño de pisos.

En el planteamiento de los resultados realizamos explicaciones, asociaciones entre aspectos encontrados en los componentes estudiados, justificaciones y demás elementos que permitan que la información tenga la consistencia y validez necesaria para la toma de decisiones. Todo lo anterior permitirá perfilar el contenido del reporte de necesidades, tema que será tratado en el siguiente apartado.

\section{Resultados}

Para ver de manera más clara la arquitectura y desarrollo urbano de la ciudad la hemos dividido cronológicamente en 5 épocas específicas: la primera, Época Colonial Siglo XVII y Siglo XVIII (Génesis de Santiago), la segunda, el periodo que abarca el final de la Época Colonial y la Unión de Panamá a Colombia (Siglo XIX) (Primera Expansión Urbana), la tercera etapa cubre el principio de Siglo XX (de 1900 a 1949) (Santiago La Pintoresca); la cuarta etapa es la Segunda mitad del Siglo XX (1950-1999) (Revolución Moderna y Urbana) y la quinta y última etapa cronológica el Siglo XXI (del 2000 a la fecha 2016) (inicio del Vanguardismo Arquitectónico y Segunda Expansión Urbana). 
En cada periodo hicimos una investigación, análisis y descripción del desarrollo de la ciudad de Santiago de Veraguas en estos años descritos, el avance en las infraestructuras, en las instituciones educativas, el desarrollo y crecimiento de las barriadas y arquitectura residencial. Como parte del desarrollo social de la ciudad.

En base a esto desglosamos los siguientes cuadros, mapas e imágenes para describir la evolución y desarrollo de la Arquitectura de la Ciudad de Santiago de Veraguas:

Época Colonial Siglo XVII, XVIII. La Época Colonial Siglo XVII (Génesis de Santiago), se toma como inicio el traslado de la ciudad de Santiago La Vieja a Santiago La Nueva 1638 (Molina Castillo, Mario José. 2013), en esta fecha existe una transición importante en el esquema poblacional de Santiago de Veragua, se construye un nuevo templo, un hospital, viviendas y trazado de las calles (Calle Real y Calle del Calvario), hoy Calle Segunda y Avenida Central y la plaza Mayor (Hoy Parque Juan Demóstenes Arosemena).

Siglo XVIII la Segunda el periodo que abarca el Final de la Época Colonial, se dan pocos cambios a la fisionomía de la ciudad, es solo para finales de Siglo XVIII, que se crean dos nuevas vecindades con la creación de dos Plazas, la Plaza San Juan de Dios y la Plazoleta San Antonio (barrio de los artesanos, afros y mestizos). (Molina Castillo, Mario José. 2013), este último ya está desaparecido al ser una de las tantas áreas como edificaciones, productos del crecimiento no planificado de la ciudad de Santiago, perdiendo con este un gran legado Colonial, en cuanto a la Plaza San Juan de Dios, ha sido alterada en gran parte, aunque su posición se mantiene.

En el Siglo XVIII la clase dominante de Santiago se concentraba en el centro de la ciudad y el resto en los campos. Es en este Siglo que se crea un mejor diseño urbanístico de la ciudad, avances en la estética y la arquitectura de las construcciones, este avance se desarrolla por el uso de mejores técnicas de construcción, mejores materiales y diseños modernos y más trabajados. Se realizan reformas a los templos existentes, se elaboran retablos, esculturas, pinturas y ornamentos de platería, donde predominan el arte con tendencia barroca.

Fueron traídos muchos maestros, de alarifes y carpinteros de lo blanco directamente de Andalucía a Santiago de Veraguas bajo la gobernación de Bejarano, muchos eran miembros de las milicias, realizaban edificaciones y ornamentaban los templos y demás necesidades comunitarias. A partir de los Siglos XVII y XVIII, algunos nativos logran desarrollar destrezas artesanales, manuales y técnicas. (Mario Molina, 2013).

Cuadro 1. Síntesis del sistema constructivo de la ciudad de Santiago de Veraguas en la Época Colonial desde el Siglo XVII hasta el Siglo XIX.

\begin{tabular}{|l|l|l|}
\hline \multicolumn{1}{|c|}{ Sistemas constructivos } & $\begin{array}{l}\text { Influencia } \\
\text { arquitectónica }\end{array}$ & Materiales \\
\hline $\begin{array}{l}\text { Casas de quincha. embarradas } \\
\text { Casas de tablas } \\
\text { Bohíos de paja. }\end{array}$ & $\begin{array}{l}\text { Arquitectura } \\
\text { criolla }\end{array}$ & $\begin{array}{l}\text { Barro, Madera, } \\
\text { Paja, carrizo, } \\
\text { Adobe, Pieles. }\end{array}$ \\
\hline $\begin{array}{l}\text { Casas de quincha. embarradas } \\
\text { Casas de tablas } \\
\text { Bohíos de paja. }\end{array}$ & & \\
\hline
\end{tabular}




\begin{tabular}{|c|c|c|}
\hline $\begin{array}{l}\text { Las casas de quincha evolucionan a casas de adobe y ladrillos } \\
\text { cocidos. } \\
\text { Edificaciones de mampostería. } \\
\text { Amplios portales empedrados, inmediato de acceso o salida a } \\
\text { los patios con solería, terraplén, lo que evitaba el lodo y la } \\
\text { humedad que afectaba a la población de esta ciudad. } \\
\text { Se empiezan a construir casas de un alto. } \\
\text { Amplios portales empedrados en el con frente del patio de las } \\
\text { casas. } \\
\text { Ventanas grandes con sus puertas } \\
\text { Algunos pisos eran pavimentados con ladrillo. } \\
\text { Algunos cielorrasos entablados. }\end{array}$ & $\begin{array}{l}\text { Influencia } \\
\text { hispano- } \\
\text { musulmán. } \\
\text { Influencia } \\
\text { barroca. } \\
\text { Arquitectura } \\
\text { criolla. } \\
\text { Barroca en los } \\
\text { templos. }\end{array}$ & $\begin{array}{l}\text { Barro. } \\
\text { Madera. } \\
\text { Paja. } \\
\text { Carrizo. } \\
\text { Adobe. } \\
\text { Pieles. } \\
\text { Hojas } \\
\text { Piedras } \\
\text { Ladrillos } \\
\text { Cal. } \\
\text { Tejas. }\end{array}$ \\
\hline $\begin{array}{l}\text { Paredes de tierra y paja, algunas acaladas (mezcla de cal y arena). } \\
\text { Cimientos en piedra y cal. } \\
\text { Se empiezan a ver paredes de ladrillo, adobes cocidos y cal. } \\
\text { El Hospital y la Iglesia San Juan de Dios se reconstruyen en } \\
\text { 1759, Con materiales más resistentes. Por primera vez se utiliza } \\
\text { una planta arquitectónica para construir un proyecto. (Mario } \\
\text { Molina, 2013). } \\
\text { Mejor apariencia arquitectónica a partir de 1759. (Mario Molina, } \\
\text { 2013). }\end{array}$ & $\begin{array}{l}\text { Arquitectura } \\
\text { criolla. } \\
\text { Arquitectura } \\
\text { con influencia } \\
\text { republicana } \\
\text { colombiana. }\end{array}$ & $\begin{array}{l}\text { Barro, Madera. } \\
\text { Paja, carrizo. } \\
\text { Adobe, Pieles. } \\
\text { Hojas, Piedras. } \\
\text { Ladrillos } \\
\text { Cal. } \\
\text { Tejas. }\end{array}$ \\
\hline
\end{tabular}

Segunda etapa (Siglo XIX) (Primera Expansión Urbana), Se heredan algunas técnicas y arte de las construcciones, de los visitantes constructores de España en Siglo XVI y XVII y realizaron obras fabulosas en el Siglo XIX, y posteriormente pasando de generación en generación se integraron obras de arquitectura que han perdurado hasta nuestros días, como las residencias de madera de Calle Segunda, incluyendo el recién demolido Hotel Santiago (demolido en Octubre del 2016), muchas de estas obras como describimos anteriormente, llegaron a formar la fisionomía de Santiago de Veraguas hasta entrada la segunda mitad del siglo XX. Podemos identificar aun elementos barrocos, arquitectura neoclásica, arquitectura autóctona panameña y se unen las influencias de la época Republicana de la Gran Colombia, con sus amplios patios y techos de tejas y terraplenes.

La ciudad de Santiago es un punto céntrico de la economía y la cultura de los poblados aledaños. Ya para 1814 existía un gran atraso urbanístico en los pueblos indígenas y en las ermitas que serán constantes en casi todo el Siglo XIX, solo existe crecimiento en los poblados de españoles y de forma lenta.

Empiezan a mostrarse la figura de los terratenientes, los grandes propietarios de terrenos que vivían en Santiago y Soná. Existían grandes extensiones de terreno que eran propiedad de pocas familias y las utilizaban especialmente para la actividad ganadera. Para finales de este Siglo XIX y principios del Siglo XX, es cuando se crea el trazado básico de la red de pueblos y la trama principal de la ciudad de Santiago y es para finales del siglo XIX que se contaba con una buena apariencia arquitectónica. 
Cuadro 2. Síntesis del sistema constructivo de la ciudad de Santiago de Veraguas en el Siglo XIX, (Primera Expansión Urbana).

\begin{tabular}{|c|c|c|}
\hline Sistemas constructivos & $\begin{array}{l}\text { Influencia } \\
\text { arquitectónica }\end{array}$ & Materiales \\
\hline $\begin{array}{l}\text { Existe también un tipo de casa para la servidumbre la } \\
\text { denominada Casa Cañón, donde vivían por lo general los } \\
\text { negros y sirvientes de la familia, separada de la residencial } \\
\text { principal. } \\
\text { Las casas algunas habían evolucionado de quincha y } \\
\text { madera, a casas con paredes de ladrillo y los techos de teja } \\
\text { con pisos de ladrillo. } \\
\text { Ya se encuentran casas de un alto. }\end{array}$ & $\begin{array}{l}\text { Arquitectura } \\
\text { criolla. } \\
\text { Arquitectura } \\
\text { con influencia } \\
\text { Republicana } \\
\text { Colombiana. }\end{array}$ & $\begin{array}{l}\text { Barro. } \\
\text { madera. Paja, carrizo. } \\
\text { Adobe, pieles, hojas. } \\
\text { piedras. } \\
\text { ladrillos. cal. } \\
\text { Tejas. }\end{array}$ \\
\hline
\end{tabular}

La arquitectura se puede clasificar de clasista las residencias de primera son para los amos y los cañones para esclavos y criados. Debido al crecimiento de la población y los foráneos que se establecen en la ciudad, la misma va cambiando en tamaño y apariencia

Tercera etapa es el principio de Siglo XX (de 1900 a 1949) (Santiago La Pintoresca). Desde principios de Siglo XX hasta llegada casi la mitad de siglo XX, la fisionomía de la ciudad de Santiago de Veraguas aún seguía teniendo matices rurales, con escasa población y calles de tierra y piedra. La arquitectura utilizada aun es la lenta evolución desde la época de su fundación, donde aún convergen varios sistemas constructivos, en el centro del poblado vemos aun las residencias en su mayoría de madera, con techos de tejas, algunas con paredes de ladrillos, otras en quincha, en las periferias de la ciudad son bohíos de paja. La apariencia de algunas edificaciones guarda elementos neoclásicos, sobre todo en las puertas y amplios portales, algunas con patios centrales y las residencias de dos altos, con sus amplios balcones. No es hasta finales de la década de 1940 que se empieza a cambiar algunas edificaciones con otros materiales como piedras, concreto y techos de zinc, después de la construcción de la Escuela Normal de Señoritas, donde su arquitectura causo gran influencia en las edificaciones de la ciudad.

Su apariencia aun para 1930 es parecida a la ciudad Colonial en forma Rectangular, es después de 1934 cuando Santiago de Veraguas sufre una nueva expansión con la construcción del Hospital a final de Calle 2da, lo que provocó la casi inmediata urbanización de sus alrededores y hacia el Este ya para 1936, la Calle del Calvario, actual Avenida Central ya llegaba hasta donde hoy se ubica el Almacén Punto Mayorista (hoy desaparecido por incendio). Para estos años aparecen lo que hoy conocemos como Calidonia, Calle 4ta., calle 5ta, como parte de la periferia de la Ciudad o barrios marginados donde se empezaron a asentar las familias más pobres.

Es después de 1936 a 1938, luego de la construcción de la Escuela Normal Juan Demóstenes Arosemena cuando cambia la forma de la fisionomía de la ciudad, en tamaño y forma arquitectónica. Para esta época aun el comercio, movimiento religioso y cívico giraba en torno a las calles principales de Santiago de Veraguas y la Placita San Juan De Dios. Los barrios residenciales relativamente compactos cerca del centro, pero la densidad residencial va disminuyendo considerablemente a medida que aumenta la distancia del centro de la población. A lo largo de la Calle del Seminario actual Avenida Central se ve un uso combinado de tierra, industrial y comercio a pequeña escala. 
Cuadro 3. Síntesis del sistema constructivo de la ciudad de Santiago de Veraguas en el principio de Siglo XX. (Santiago La Pintoresca).

\begin{tabular}{|c|c|c|}
\hline Sistemas constructivos & $\begin{array}{l}\text { Influencia } \\
\text { arquitectónica }\end{array}$ & Materiales \\
\hline $\begin{array}{l}\text { Las casas de las calles principales de la ciudad eran de madera con } \\
\text { amplios portales y techos de teja, con diseño que contaban con mucha } \\
\text { comodidad y mucha ventilación. Portales grandes y frescos en su parte } \\
\text { frontal. } \\
\text { Puertas amplias y ventanales bien elaborados. } \\
\text { En la parte frontal barandales metálicos. } \\
\text { Algunos Edificios de madera de dos plantas (como la Escuela } \\
\text { Dominio del Canadá), con un largo balcón y arquitectura tipo colonial } \\
\text { armónico estructuralmente y amplio patio interior con altos arboles de } \\
\text { almendras en la parte derecha del patio una pared amurallada. } \\
\text { En los sectores aledaños las casas eran de quincha con amplios solares } \\
\text { y rodeada de árboles frutales. Aun las fincas en las afueras de la ciudad } \\
\text { no eran cercadas se trazaban líneas delimitantes imaginarias tomando } \\
\text { en cuenta límites geográficos o de la naturaleza. } \\
\text { Para } 1902 \text { la ciudad de Santiago de Veragua, se encuentran en un } \\
\text { estado deplorable, producto del abandono que se ha dado de parte del } \\
\text { Gobierno Colombiano, no existe agua potable, ni acueductos, ni } \\
\text { cloacas, ni desagües y las calles en pésimo estado. Existe un atraso en } \\
\text { la fisionomía urbana en comparación a otras ciudades del mundo. }\end{array}$ & $\begin{array}{l}\text { Arquitectura } \\
\text { criolla. } \\
\text { Arquitectura } \\
\text { con influencia } \\
\text { republicana } \\
\text { colombiana. } \\
\text { Arquitectura } \\
\text { neoclásica a } \\
\text { partir de } 1938 .\end{array}$ & $\begin{array}{l}\text { Barro. } \\
\text { madera. } \\
\text { paja. } \\
\text { carrizo. } \\
\text { adobe. } \\
\text { pieles. } \\
\text { hojas. } \\
\text { Piedras. } \\
\text { Ladrillos } \\
\text { Cal. } \\
\text { Tejas. } \\
\text { Vidrios. } \\
\text { Hierro. } \\
\text { Zinc. } \\
\text { Cemento. } \\
\text { Mosaico } \\
\text { Pintura. } \\
\text { Acero. }\end{array}$ \\
\hline $\begin{array}{l}\text { Entre } 1910 \text { y } 1920 \text { la ciudad de Santiago extendió su espacio quedando } \\
\text { al Norte hasta la intersección de Calle } 2 \text { da. Con la carretera actual que } \\
\text { conduce a Soná y al Sur limitado por las primeras casas de lo que hoy } \\
\text { se conoce como La Tronoza, al Este hasta el punto que hoy se ubica } \\
\text { el Edificio de la Asociación de Educadores Veragüenses, intersección } \\
\text { de la Avenida Central y Calle Adolfo J. Fábrega y al Oeste limitado por } \\
\text { la Calle del Chorrillo, hoy Calle Primera. Fuera de estos linderos } \\
\text { existió un pobre caserío conocido como Flamenco, de rancho de paja } \\
\text { y humildes chozas, ubicado al este entre la actual calle 8va. Y calle 9na. } \\
\text { Y la Avenida Central y Carlos A. Torraza. }\end{array}$ & & \\
\hline
\end{tabular}

Cuarta etapa es la Segunda mitad del Siglo XX (1950-1999) (Revolución Moderna y Urbana). A partir de este periodo es cuando se da la ruptura definitiva de la arquitectura tradicional que se había mantenido por más de 3 siglos y medio y no había sufrido cambios tan radicales, sobre todo con la apertura de la Vía Interamericana, gracias a ella se lograría el acceso más fácil a los materiales y personal dedicada a la construcción y que aceleraría el proceso de cambio. Por segunda vez, la ciudad de Santiago consigue estar paralelo en los adelantos tecnológicos de la construcción que se daba en la ciudad capital y otras ciudades del país. Las residencias y edificaciones pasan a modelos de vanguardias de la época, la arquitectura moderna, residencias tipo chalet y modelos utilizados en las barriadas construidas por el Estado, de tipo de interés social. 
En la ciudad existe un contraste con lo moderno y lo antiguo, su forma ha cambiado, de la anterior forma rectangular de principio de Siglo XX, a la forma lineal de los años '60, ahora para los años '70 la ciudad de Santiago de Veraguas tiene una apariencia irregular, parecida a una "C" mayúscula. Hacia el Sur de la Ciudad crece hacia la parte oriental hasta llegar a la Vía Interamericana y hacia el Norte se empiezan a utilizar las tierras húmedas, inundables.

\section{Cuadro 4. Síntesis del sistema constructivo de la ciudad de Santiago de Veraguas en la Segunda mitad del Siglo XX (1950-1999) (Revolución Moderna y Urbana).}

\begin{tabular}{|c|c|c|}
\hline Sistemas constructivos & $\begin{array}{c}\text { Influencia } \\
\text { arquitectónica }\end{array}$ & Materiales \\
\hline $\begin{array}{l}\text {-Para la década de los años ' } 50 \text { la fisionomía de la Avenida Central de } \\
\text { Santiago era muy diferente a lo que hoy conocemos, sus residencias y } \\
\text { locales aún son para esta fecha la mayoría estructuras de madera, con } \\
\text { techos de zinc o tejas, muy pocas de dos plantas. } \\
\text { - En la década de los '60, las residencias en su mayoría, son de una planta } \\
\text { tipo unifamiliar y aislada, construidas en materiales de cemento con } \\
\text { cubierta de zinc. } \\
\text {-La mayor parte de los locales cercanos, que eran pocos en esta época, } \\
\text { cercanos al Mercado Publico, eran construcciones en madera y techo de } \\
\text { tejas. } \\
\text { - -La apertura de la Carretera Interamericana en 1967, causo gran influencia } \\
\text { en el crecimiento físico de la ciudad, se realizaron nuevas construcciones, } \\
\text { nuevas infraestructuras, calles y vías de penetración a partir de } 1970 \text {. Se } \\
\text { empiezan a contar con nuevas infraestructuras físicas de uso público, } \\
\text { edificios de oficina y servicio de mayor inversión en infraestructura y } \\
\text { construcciones de empresas privadas. } \\
\text {-Después de } 1970 \text { se utiliza mucho el sistema de piso pulido, algunas veces } \\
\text { se le coloca tintes de colores, en las residencias de clase media y clase } \\
\text { media-alta. En la clase alta se utiliza baldosas y mosaicos. } \\
\text {-Entre } 1970 \text { a } 1990 \text {, muchas casas antiguas, se remodelaron y ampliaron, se } \\
\text { les coloca cielorraso, repello en las paredes, acabado de mosaico en los } \\
\text { pisos, se han cambiado las puertas originales, se les ha colocado armarios, } \\
\text { muebles de cocina y ampliaciones a estas residencias. } \\
\text {-En } 1972 \text { se dan las invasiones a la barriada Alto Cuvibora y El Forestal, } \\
\text { Las primeras viviendas que se establecieron en las nuevas barriadas fueron } \\
\text { de materiales temporales y luego se fueron mejorando. } \\
\text { Gran parte de estas viviendas estaban construidas en zinc, cemento, paja, } \\
\text { cartón y quincha. } \\
\text {-Se abre para esta fecha la extensión de la Avenida Central conocida como } \\
\text { Avenida Héctor Alejandro Santa Coloma que une la Avenida Central con } \\
\text { la Vía Interamericana. Para } 1970 \text { en la Provincia de Veraguas se cuenta con } \\
\text { más de } 600 \\
\text { establecimientos comerciales, entre grandes y pequeños, de carácter } \\
\text { industrial y comercial. }\end{array}$ & $\begin{array}{l}\text { Arquitectura } \\
\text { criolla } \\
\text { arquitectura } \\
\text { con influencia } \\
\text { republicana } \\
\text { colombiana, } \\
\text { aunque } \\
\text { minimiza-da, } \\
\text { más se nota en } \\
\text { las haciendas y } \\
\text { fincas. } \\
\text { Arquitectura } \\
\text { neoclásica en } \\
\text { algunos } \\
\text { detalles. } \\
\text { Arquitectura } \\
\text { moderna. } \\
\text { Residencias de } \\
\text { interés social } \\
\text { promovida por } \\
\text { el gobierno. }\end{array}$ & $\begin{array}{l}\text { Bloques } \\
\text { Tejas. } \\
\text { Vidrios. } \\
\text { Hierro. } \\
\text { Zinc. } \\
\text { Cemento. } \\
\text { Mosaico } \\
\text { Acero. } \\
\text { Convitec. } \\
\text { Baldosas. } \\
\text { Persianas. } \\
\text { Ventanas } \\
\text { francesas. } \\
\text { Panalit. } \\
\text { Tejalit. } \\
\text { Aluminio } \\
\text { Formica. } \\
\text { Foam. } \\
\text { Arena. } \\
\text { Piedra. }\end{array}$ \\
\hline
\end{tabular}


-Se rehabilitan las carreteras hacia San Francisco, hacia Montijo, La Colorada y la Vía Interamericana, entre otras, acelerando el ritmo de desarrollo en las áreas aledañas a estas. También se amplían las calles que conducen a La Peana o la comunidad de los trabajadores. Estas vías de comunicación no eran nuevas, ya existían desde que nacieron estos poblados, pero con su rehabilitación se aceleró el proceso de construcción de nuevas viviendas

-Con el mejoramiento de las calles y avenidas, cercanas a la nueva barriada Urracá, en 1973, construida para funcionarios del Ministerio de Desarrollo Agropecuario M.I.D.A. y otras instituciones, aparecen, aprovechando este mejoramiento en infraestructuras, nuevos caseríos como El Paraíso 1 y Paraíso 2. Con la creación del C.R.U.V., se desarrollan nuevas viviendas en Canto del Llano, San Martin y la barriada 3 de noviembre (cerca del actual Forestal).

-Para esta época se da un desarrollo en las barriadas nuevas, parcelaciones y se incrementan las invasiones improvisadas lo que incrementa la población en la ciudad de Santiago de Veraguas.

-Para el año 1973, la Nación de Panamá cedió al Municipio de Santiago, más de la mitad de sus tierras en cuanto a propiedad del sector público se refiere para esta época, esto se hizo a través del Ministerio de Hacienda y Tesoro

- Para los años ' 80 ya la apariencia de algunas barriadas de emergencia había variado, ya algunas residencias se habían mejorado en su estructura.

-Para la década de 1990, las condiciones sanitarias en su mayoría son satisfactorias y las viviendas son construidas de bloques, ladrillo, piedra y zinc.

La arquitectura sigue su rumbo imparable hacia la modernidad, casi dejan en el olvido los elementos neoclásicos, durante el periodo restante del Siglo XX, en este periodo es cuando cambia definitivamente la estética de las edificaciones, la Avenida Central actual es producto de este periodo el cual avanza en mayor escala en la siguiente década, se realizan edificaciones de dos y tres altos en concreto.

Surgen también invasiones a los terrenos municipales, por parte de grupos migratorios, que trae como consecuencia la falta de servicios vitales como abastecimiento de agua potable, luz eléctrica y otros servicios fundamentales.

Para la década de los '80 se observa un gran movimiento migratorio en la Provincia de Veraguas. El crecimiento de la población en la ciudad de Santiago para la década de 1980, se debe al gran número de servicios públicos e instituciones creadas desde 1970 hasta la fecha, al igual que la apertura de la Vía Interamericana y otros elementos que crearon el ambiente preciso para que existiera una migración de personas de todos los Distritos hacia Santiago y de otras partes de la Republica. Es en esta época cuando se desarrolla la fisionomía de la ciudad que conocemos hoy. Se modernizan las estructuras urbanas. 
La arquitectura predilecta aún sigue siendo la arquitectura moderna y algunos ejemplos postmodernistas, al final de este siglo se ven algunos elementos Minimalistas, se realizan muchos diseños realizados por arquitectos de la ciudad capital y algunos extranjeros. Se empieza a dar una reminiscencia por elementos neoclásicos y en muchas ocasiones mezclándolas con elementos modernos para elaborar obras de arquitectura ecléctica, como algunos colegios, centros comerciales, plazas, residencias, edificios estatales, donde utilizan arcos y columnas clásicas, pero con mucha abstracción hacia la geometría. La arquitectura residencial se sigue expandiendo a las periferias de la ciudad, creando un poblamiento que se acerca a los poblados antes alejados de la ciudad. Los modelos de residencia son tomados de modelos realizados en la ciudad capital y otras ciudades. La ciudad de Santiago es de las más modernas del país y con mayor crecimiento, ya empiezan a entrar edificaciones comerciales con modelos y diseños arquitectónicos universales por sus franquicias, sobre todo en la Vía Interamericana. Ver fotografía 4.

Última etapa cronológica el Siglo XXI (del 2000 a la fecha 2016) (inicio del Vanguardismo Arquitectónico y Segunda Expansión Urbana). Es para esta época, cuando por primera vez en la historia, que los sistemas constructivos de Santiago y los materiales utilizados en las construcciones, están a la vanguardia con los utilizados en la ciudad capital (no en tamaño, pero si en calidad) e inclusive por encima de muchos países de Centroamérica. Esto es consecuencia en parte, por el traslado de nuevas casas comerciales nacionales e internacionales, personal capacitado y los adelantos de la tecnología. Es en este Siglo cuando se mezclan diversos estilos arquitectónicos, ya no predomina la arquitectura moderna, evoluciona a los diseños postmodernistas, minimalistas, eclecticismo y confluyendo con neoclasismo y algunas edificaciones que tratan de combinar lo vanguardista con lo tradicional. Se amplía la zona urbana de Santiago de Veraguas se crean nuevas barriadas a una velocidad nunca vista en la Ciudad, se crean nuevas estructuras, puentes y edificaciones que ayudan al desarrollo de la misma. En comparación a 1990 se ha incrementado los proyectos residenciales en un 156 \%. Para el año 2000 solo en el área de Canto del Llano existían 29 barriadas.

Cuadro 5. Siglo XXI (del 2000 a la fecha 2016) (inicio del Vanguardismo Arquitectónico y Segunda Expansión Urbana).

\begin{tabular}{|c|c|c|}
\hline & \multirow{2}{*}{$\begin{array}{l}\text { Influencia } \\
\text { arquitectónica }\end{array}$} & \multirow[t]{2}{*}{ Materiales } \\
\hline Sistemas constructivos & & \\
\hline \multirow{6}{*}{$\begin{array}{l}\text {-Es para esta década que los sistemas constructivos de Santiago y } \\
\text { los materiales utilizados en las construcciones, están a la } \\
\text { vanguardia con los utilizados en la ciudad capital e inclusive por } \\
\text { encima de muchos países de Centroamérica. Esto es consecuencia } \\
\text { en parte, por el traslado de nuevas casas comerciales nacionales e } \\
\text { internacionales, personal capacitado y los adelantos de la } \\
\text { tecnología. }\end{array}$} & \multirow{7}{*}{$\begin{array}{l}\text { Arquitectura } \\
\text { Neoclásica en } \\
\text { algunos } \\
\text { detalles. } \\
\text { Arquitectura } \\
\text { moderna. } \\
\text { Arquitectura } \\
\text { postmoderna. }\end{array}$} & Bloques, \\
\hline & & Tejas, Vidrios. \\
\hline & & Hierro. Zinc. \\
\hline & & Cemento. \\
\hline & & Mosaico \\
\hline & & Pintura. \\
\hline \multirow{2}{*}{$\begin{array}{l}\text {-Para 2012, se empieza a utilizar instalación de paneles solares, en } \\
\text { proyectos de inversión social. }\end{array}$} & & Acero. \\
\hline & $\begin{array}{l}\text { Arquitectura } \\
\text { minimalista. }\end{array}$ & Soldadura, M2. \\
\hline
\end{tabular}


La Avenida Central actualmente, sigue siendo el núcleo del Comercio desde la Intersección de la Calle décima, antigua Estación Sierra, hasta la Iglesia Catedral Santiago Apóstol, aunque en la Vía Interamericana en los últimos años se están estableciendo varios proyectos que descentraliza estas actividades comerciales. En el recorrido de la Avenida Central encontramos bancos, almacenes, casinos, servicios públicos, internet cafés, supermercados, locales electrónicos, mueblerías, farmacias, el edificio de la Asociación de Educadores Veragüenses, la Biblioteca Pública "Julio J. Fábrega", oficinas de Correos y Telégrafos, Placita San Juan de Dios, Banco Nacional de Panamá, panaderías, zapaterías, restaurantes, locales de ropa americana y edificios de apartamentos y oficinas.

\section{Discusión}

Esta investigación, plasma de manera profunda y científica esta documentación, que era necesaria en la ciudad de Santiago, poca estudiada desde el punto de vista arquitectónico, analizada desde su estructura, estética, evolución y desarrollo, infraestructura, sistema constructivo, bien organizado y desarrollado para comprender estos elementos desde el punto de vista técnico, desde sus inicios hasta la fecha. Afloran de la misma investigación, el análisis de la problemática que enfrentan estas edificaciones en el área de Casco Viejo de la ciudad lo que permitió agrupar posibles causas que inciden en la pérdida de integridad, entre ellas:

- La persistencia de prejuicios hacia el patrimonio arquitectónico del siglo XX, dada su amplia proliferación y cercanía en el tiempo, considerándose en mayor medida el aporte del período colonial a la identidad local y regional.

- Incorrecta apreciación y desconocimiento de los valores estético, histórico, cultural y ambiental de esta arquitectura, debido a la expresión modesta asumida en correspondencia con la clase media y proletaria que asimiló estos códigos.

- Limitada tutela y manejo del patrimonio arquitectónico por parte de los organismos del territorio.

En la ciudad de Santiago de Veraguas se visualizan los cambios que, desde la época Colonial hasta el siglo XXI, las edificaciones se han modificado totalmente, no se mantiene ningún vestigio de su antigua arquitectura, la cual se mantuvo en gran parte hasta mediados de los años '60 del Siglo XX, donde se dio paso a la modernización que acabo con toda la arquitectura y fisionomía Colonial y del Siglo XIX. El diseño urbanístico de la ciudad del Siglo XVII, XVIII y XIX, que logró avances en la estética y la arquitectura de las construcciones, con el uso de mejores técnicas de construcción, mejores materiales y diseños modernos y más trabajados, lo hemos podido categorizar, desde la evolución de construcciones de quincha o adobe, a ladrillos cocidos y mampostería, techo de tejas y pisos cubierto con ladrillos, identificando elementos barrocos, arquitectura neoclásica, arquitectura autóctona panameña, luego pasando con las modificaciones del Siglo XX y el actual Siglo XXI.

Esta evolución se ha dado de manera especial y única, situación que permitió el análisis de muchas variables para poder realizar su clasificación en los cinco grupos ya descritos. Hasta mediados del siglo $\mathrm{XX}$, estos cambios se hacen de manera lenta, y se aceleran, en parte por la influencia de la arquitectura de la Escuela Normal Juan Demóstenes Arosemena y otros proyectos estatales, la incorporación a la población de Santiago de algunos constructores de estas obras, los cuales empezaron a residir en la ciudad y otros brindaron sus conocimientos para que se formaran las siguientes generaciones de trabajadores de la construcción que aportarían el cambio de las edificaciones de la ciudad. 
En la década de los '50 que se empieza a poblar las barriadas de Paso Las Tablas y Alto Alfaro y aparecen las primeras viviendas de Las Delicias, Canto del Llano y San Martin. Este crecimiento no va a detenerse y va a expandirse a través de la historia. Aunado al crecimiento de la Avenida Central, desde finales de década del 70, la cual fue muy rápida, y de forma algo desordenada y con un diseño arquitectónico poco armonioso, las alturas de los locales y sus tamaños creció contando con edificios hasta de 3 o 4 plantas, antes no visto en la ciudad. El trazado de la Carretera Interamericana en 1967, a partir de este momento la Carretera Nacional, procedente de David deja de cruzar el Centro de la Ciudad de Santiago, pero trae como resultado la modernización y facilidad de nuevos materiales de construcción y se acelera el crecimiento de la ciudad. Pasando por una migración descontrolada de la década de los 80, la cual trajo como consecuencia la saturación de los servicios públicos, e invasiones de áreas sin planificación, pasamos a la década del 90 donde crece el sector comercial y se nota a lo largo de la Avenida Central se ve un uso combinado de tierra, industrial y comercio a pequeña escala. El mercado y terminales de transporte están cerca de la Placita San Juan De Dios. Aunque se incrementan las viviendas de emergencia en las afueras del núcleo urbano, debido a la migración de la población hacia Santiago de Veraguas.

En el Siglo XXI, con el establecimiento de comercios transnacionales y nacionales, con sus diseños arquitectónicos establecidos y de vanguardia, inicia un nuevo cambio en la arquitectura con una tendencia hacia las vanguardias internacionales; todavía, de manera algo moderada por la aceptación de la población santiagueña, al causar una gran ruptura a la arquitectura tradicional y un cambio acelerado de la misma. Muchos de los inversionistas del área aun prefieren las reminiscencias de una arquitectura tradicional y moderna, en ocasiones aburrida, simple y muy criticada por las nuevas generaciones, que ven nuevas alternativas, ya sea de la capital, en viajes y por información digital. Se observa un cambio en la tendencia, en un mercado que está de regreso a la ciudad de Santiago para residir o trabajar y pide nuevos ambientes y estructuras en la ciudad. Por lo cual no cerramos aquí el capito pues solamente inicia el desarrollo de la misma.

Otro aspecto de resaltar es que la Vía Interamericana, desde Divisa hasta Las Palmas, muestra gran cantidad de comercios, industrias y áreas residenciales e institucionales. Actualmente, es la vía donde el desarrollo de las construcciones se está dando de una manera más acelerada, para los próximos años tendremos un desarrollo comercial más grande en esta vía y esto incrementa el crecimiento de la ciudad y de todos los que transitan por esta vía. Pero quedan muchos retos por superar, como los nuevos planes de ordenamiento de la ciudad, la modernización de los servicios públicos y la carencia de facilidades de infraestructura que abarquen las grandes necesidades de la ciudad. Este estudio sirve de base para entender el crecimiento y tendencia de las formas constructivas de la ciudad y a la vez analizar sus aciertos y errores que podamos corregir para tener una mejor ciudad.

\section{Conclusiones}

Toda disciplina o profesión necesita una base documentada para realizar propuestas, investigaciones y diagnósticos, mismos deben ser efectivos para soluciones a un sinnúmero de problemas que hoy afectan nuestras ciudades. Sin tomar en cuenta los antecedentes y la evolución de las mismas, es muy difícil llegar a resultados satisfactorios de cualquier tipo que se realicen en un área específica.

Tomando en cuenta los aspectos planteados, la situación problemática consiste en: la necesidad de profundizar en los estudios acerca del patrimonio arquitectónico en la ciudad de Santiago de Veraguas, para completar los vacíos existentes en la historiografía arquitectónica local. 
También, la forma en la que ha crecido esta ciudad, por su sobre poblamiento, causa problemas sociales y de infraestructura, sobre todo en las barriadas emergentes. De aquí se desprende la necesidad de actualizar el plan de zonificación de la ciudad y un plan maestro para el planeamiento y organización de la ciudad a futuro, el cual ya tiene más de 40 años de implementación, tiempo en el cual la ciudad ha sufrido grandes cambios y los sigue sufriendo.

En cuanto a la estética y tendencias arquitectónicas, organizado desde el punto de vista teóricohistórico y cronológico, observando que se ha introducido arquitectura de vanguardia en la ciudad de Santiago, la cual va a seguir incrementando de manera más acelerada y continua, ocasionando grandes cambios para la fisionomía de Santiago. Todo este planteamiento ayudará a un enfoque y propuestas futuras más cónsonas y claras en esta línea y otras que sean meritorias.

\section{Referencias}

Caballé, I. y Esteve, F. (2003). Arquitectura y Documentación: arqueología de la vivienda en el Casco Antiguo de Barcelona. Revista Scripta Nova, 2003.

Carles, R. D. (1969) 220 años del período colonial en Panamá. Panamá.

Castillero Calvo, A. (1995). Conquista evangelización y resistencia. Panamá: Editorial Mariano Arosemena

Castillero Calvo, A. (1967) Estructuras sociales y económicas de Veragua desde sus orígenes históricos siglo XVI y XVII. Panamá: Editora Panamá.

Garré, F. (2001.) Patrimonio arquitectónico urbano, preservación y rescate: bases conceptuales e instrumentos de salvaguarda. Revista Conserva.

Grout, L. N., Wang, D. (2010). Architectural Research Methods. (2a. ed.).

Molina Castillo, M. J. (2013). Veragua: Tierra de Colón y de Urraca. Panamá: Arte Gráfico Impresores.

Osorio Osorio, A (2000). Historia eclesiástica de Panamá: 1815-1915. Panamá: Grupo Arroba.

Puente San Millan (2014). Arquitectura Art Decó en el Centro Histórico de la ciudad de Santiago de Cuba. La Habana, Cuba: Universidad Tecnológica de La Habana, Facultad de Arquitectura.

Valdeón, J., Salrach, J. M. y Zabalo, J. (1987). Feudalismo y consolidación de los pueblos hispánicos. Barcelona: Labor. 


\section{Anexos}
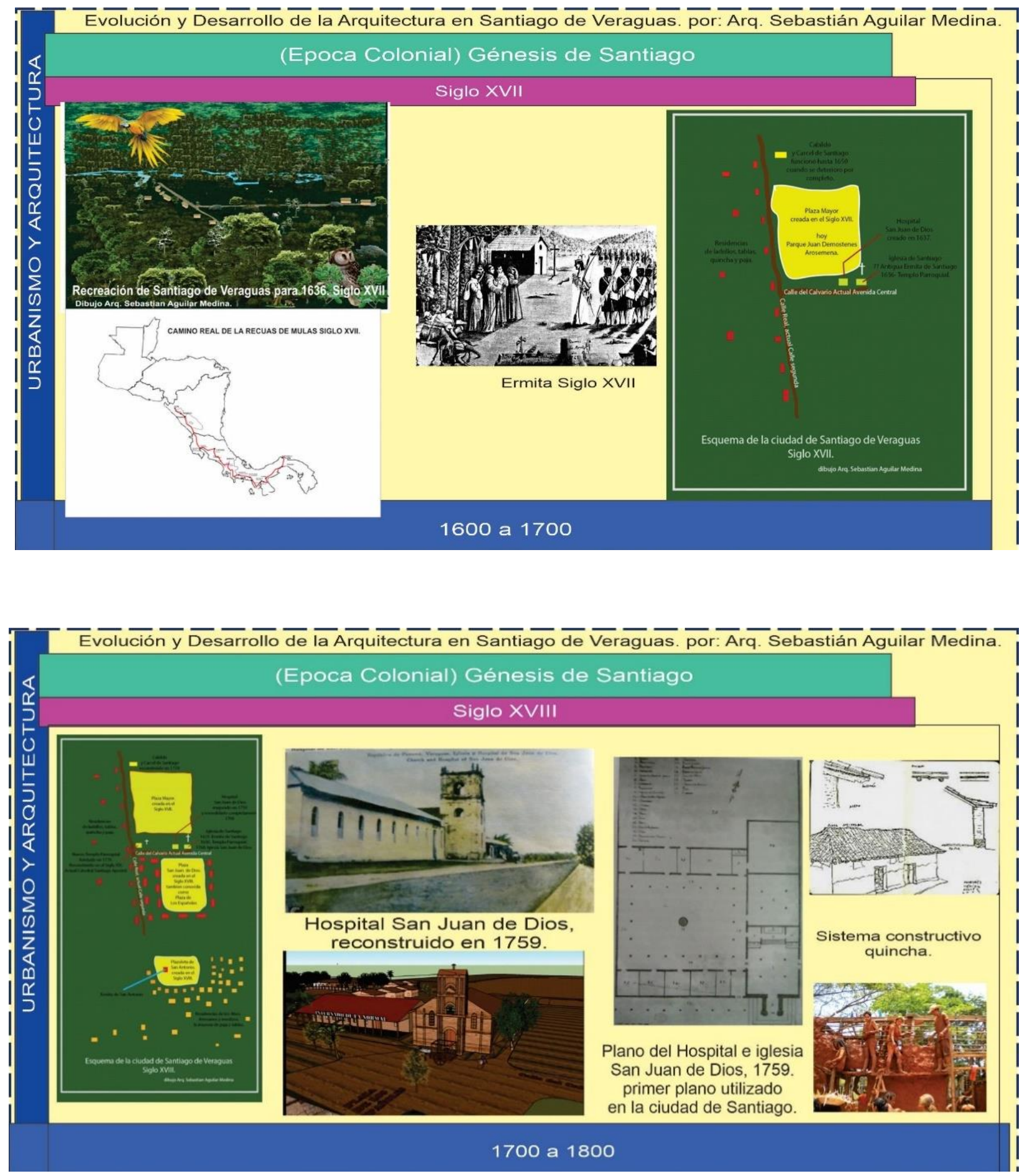

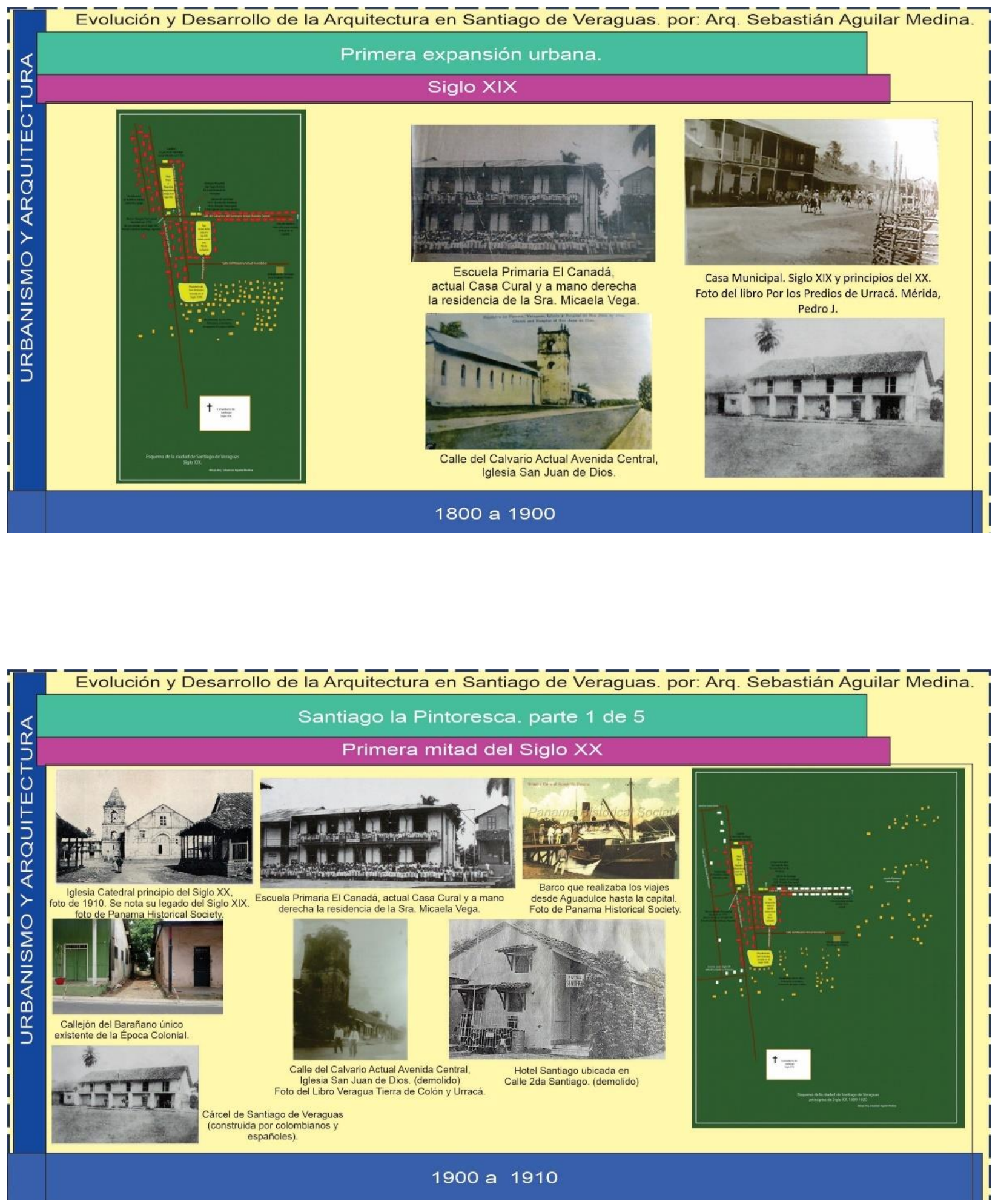

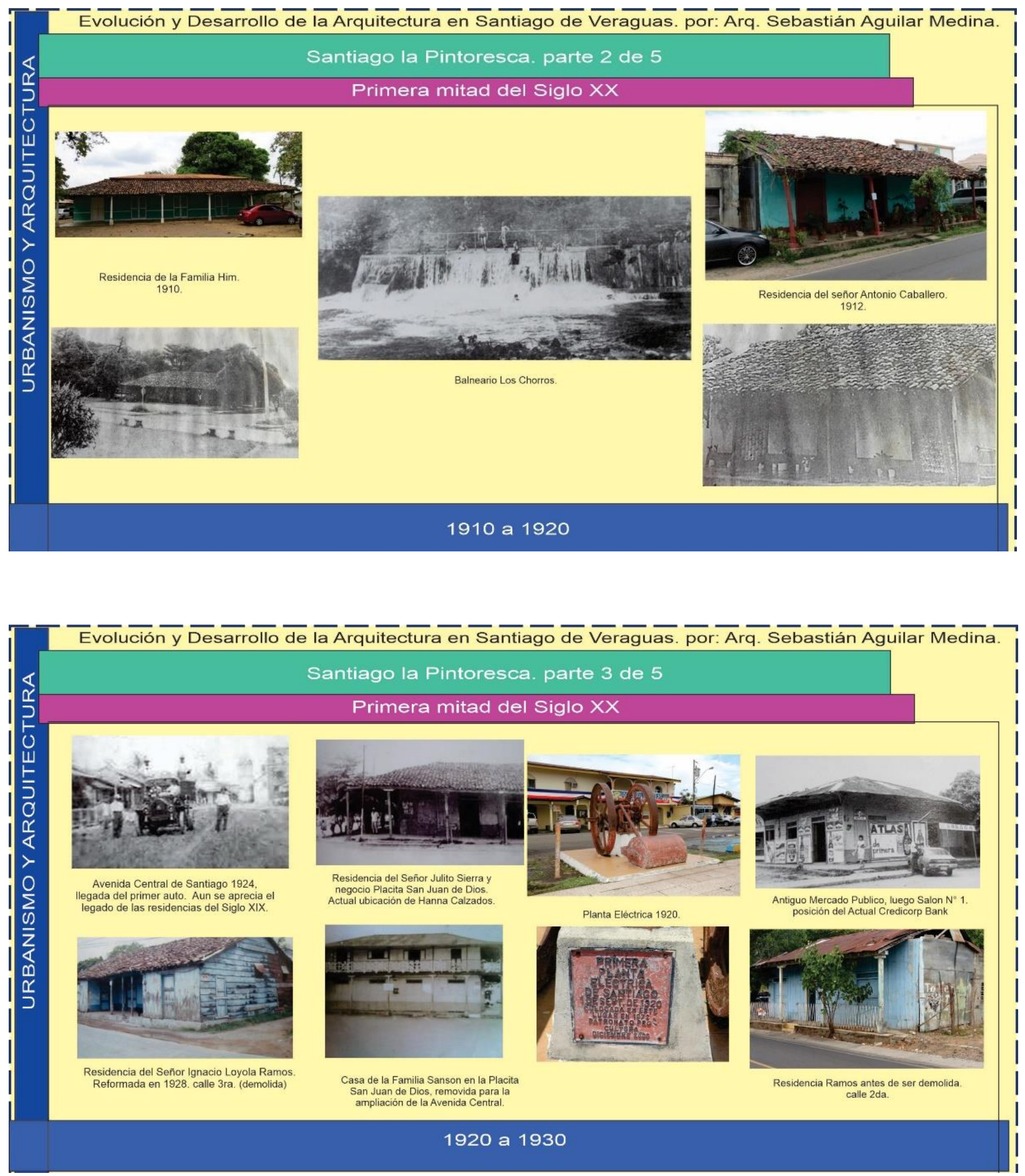

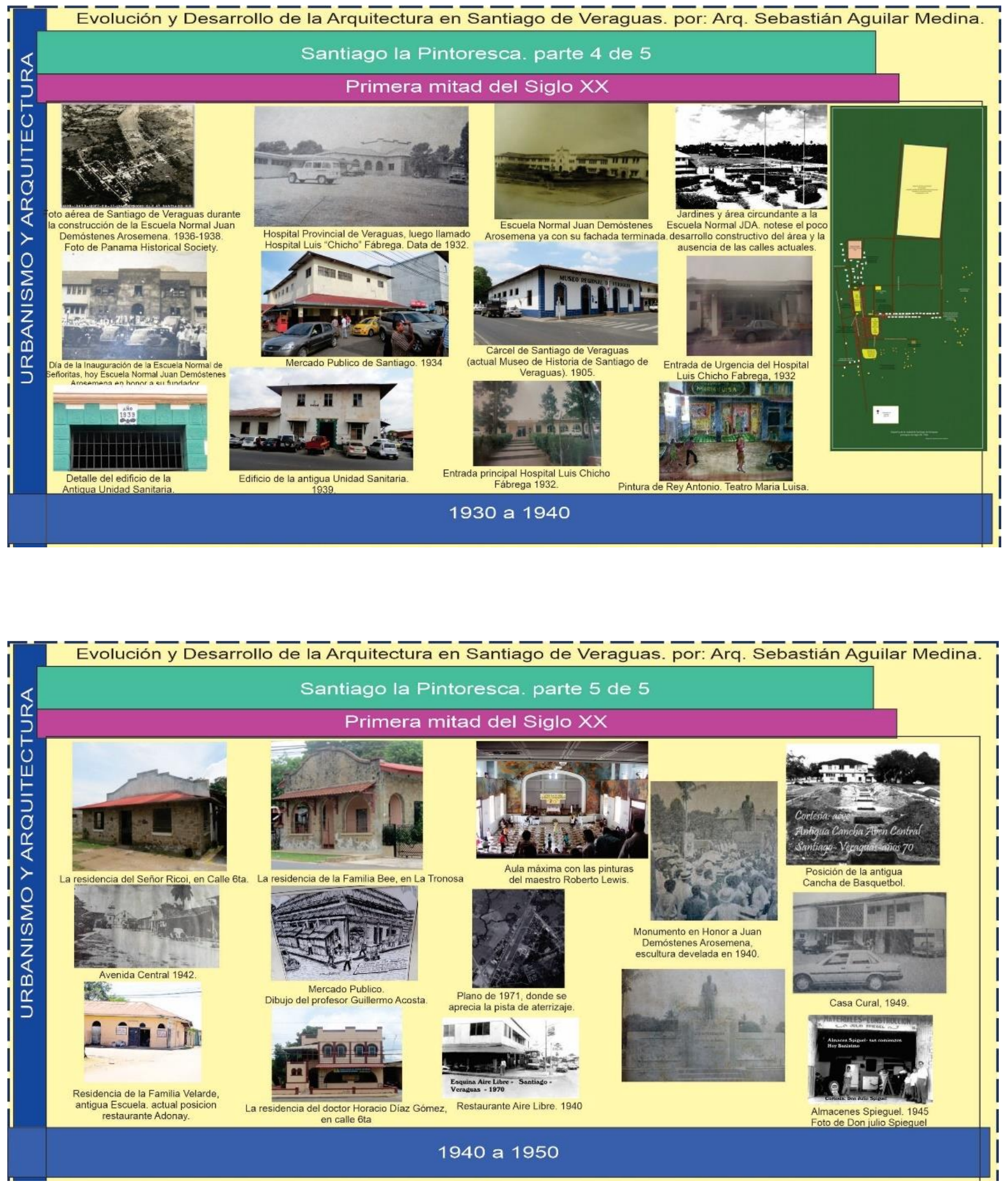

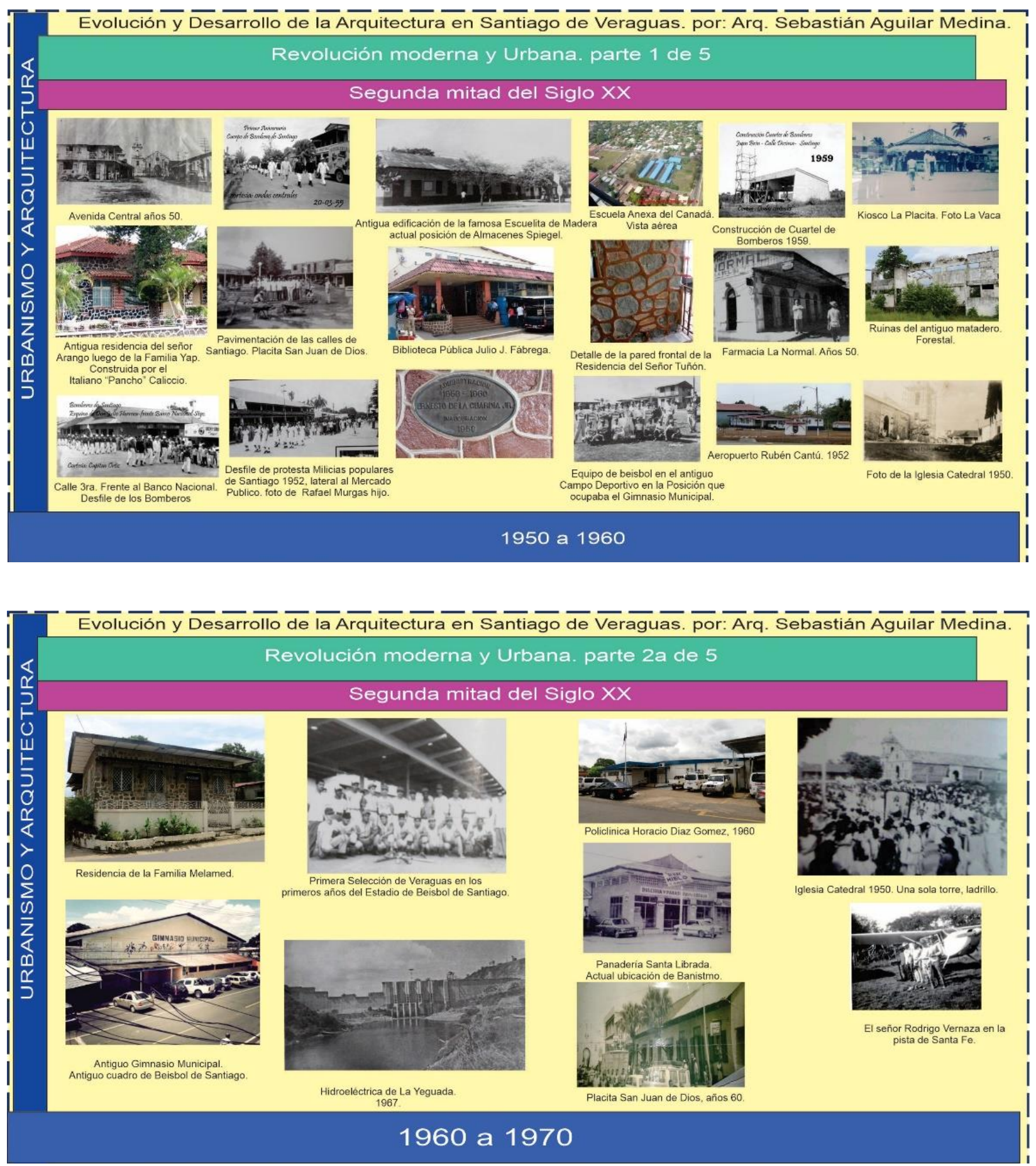

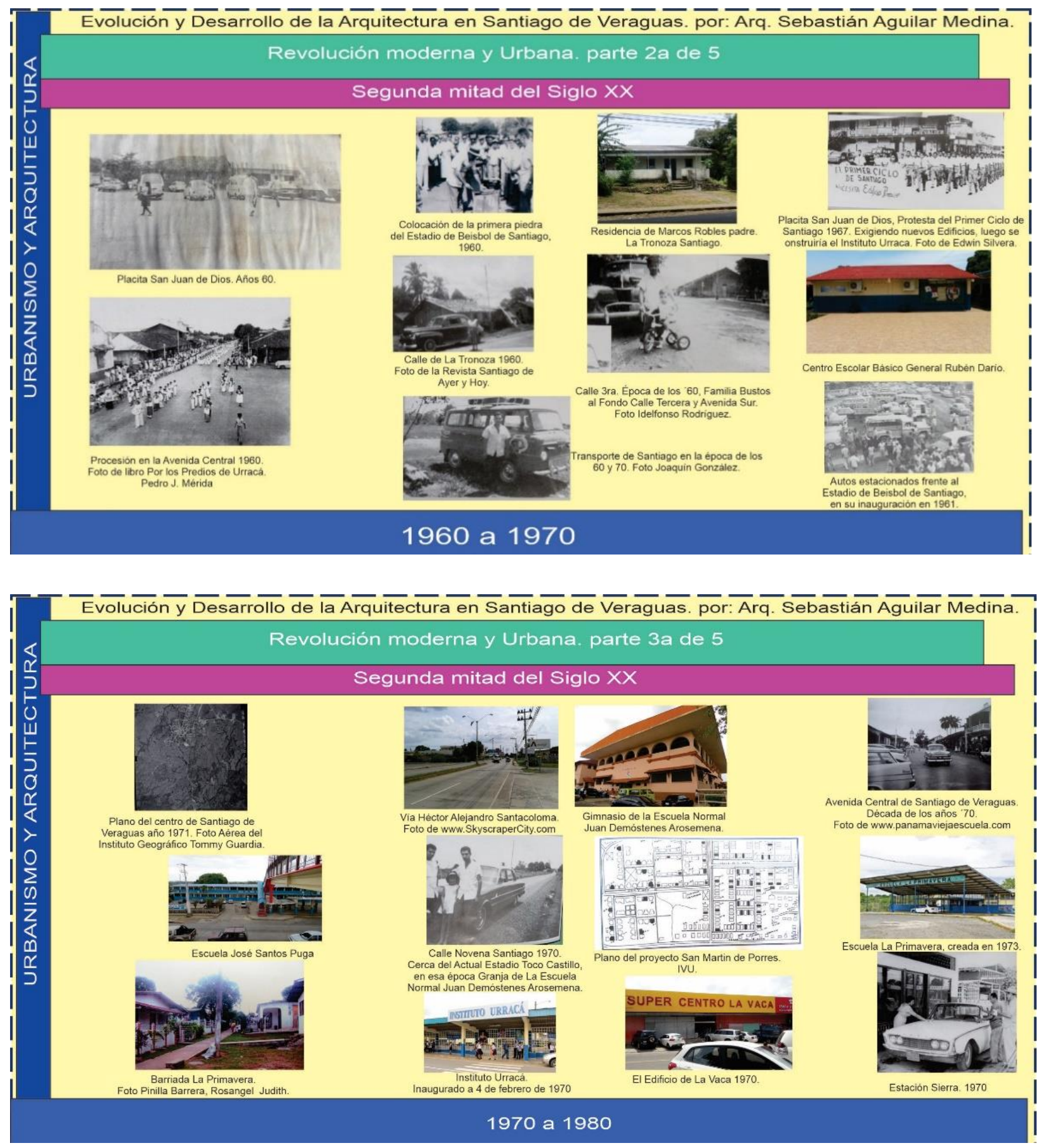

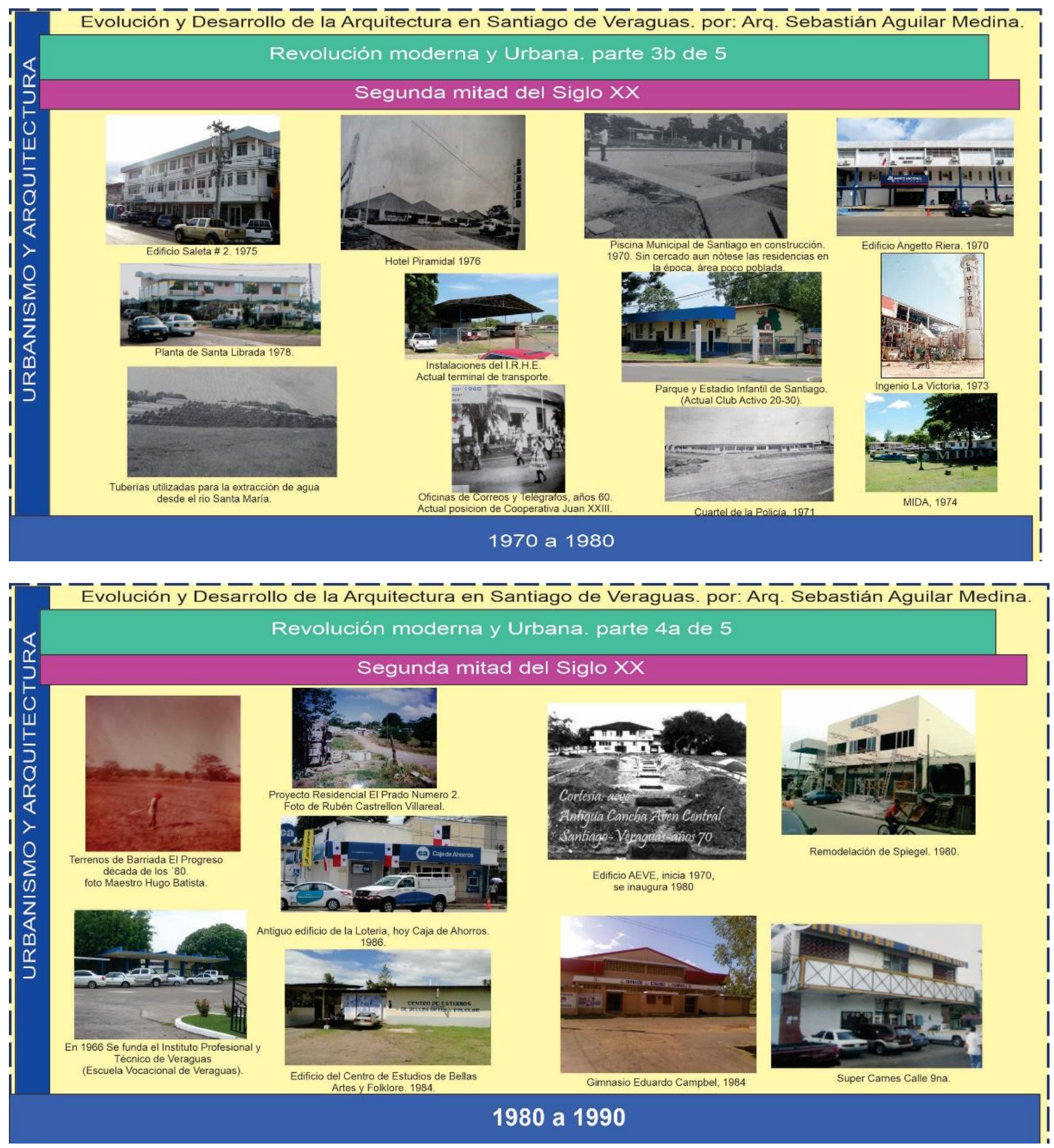

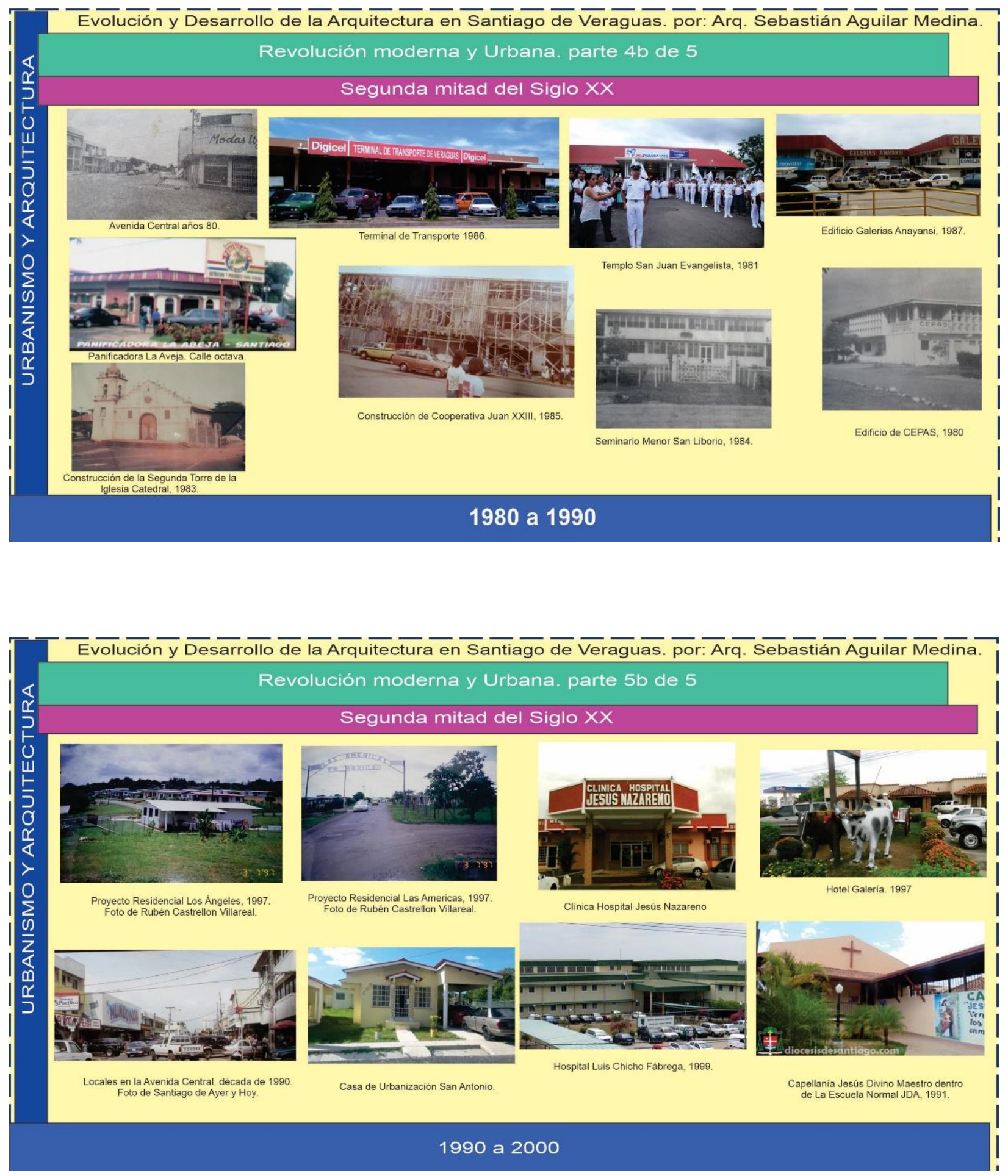

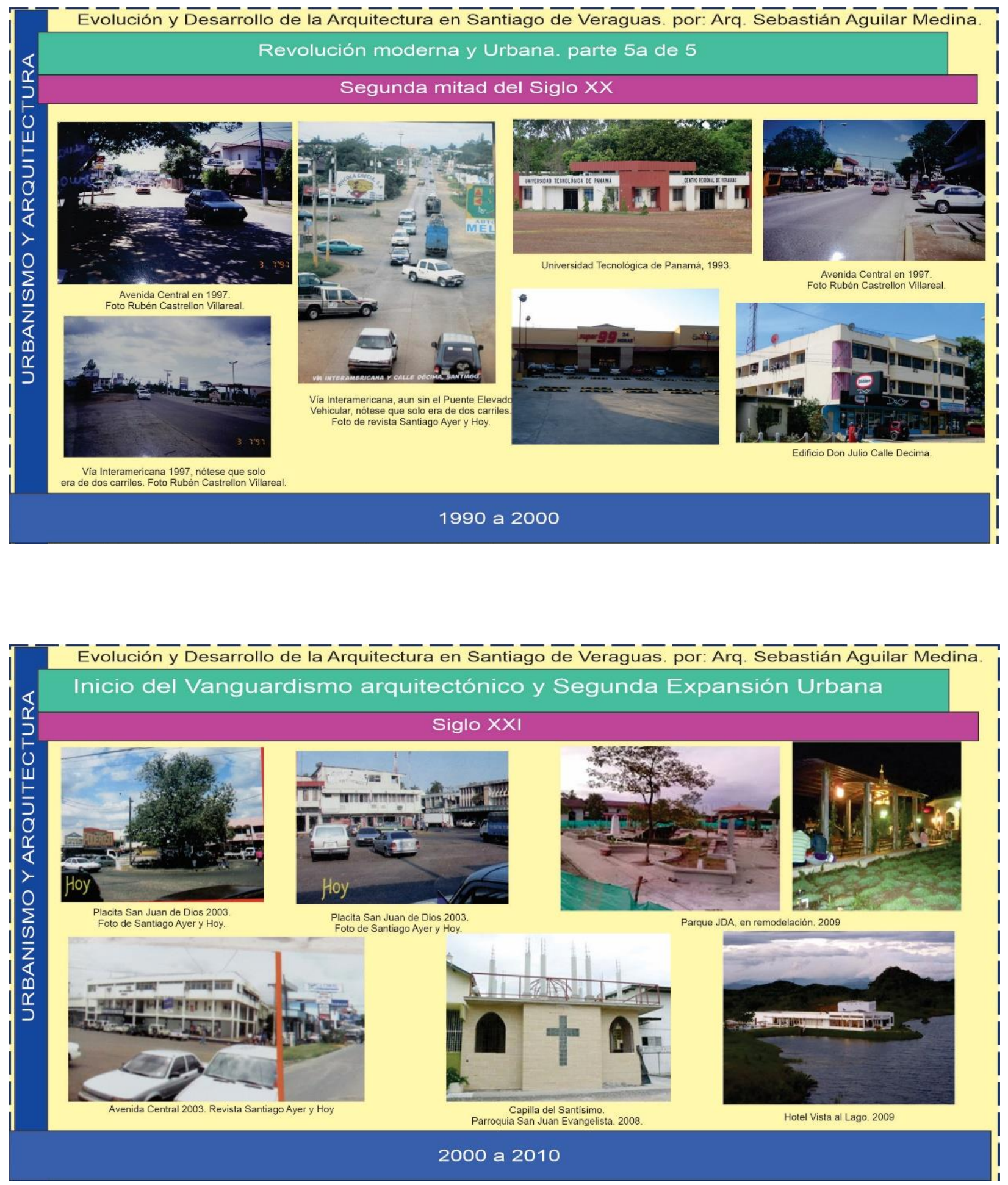

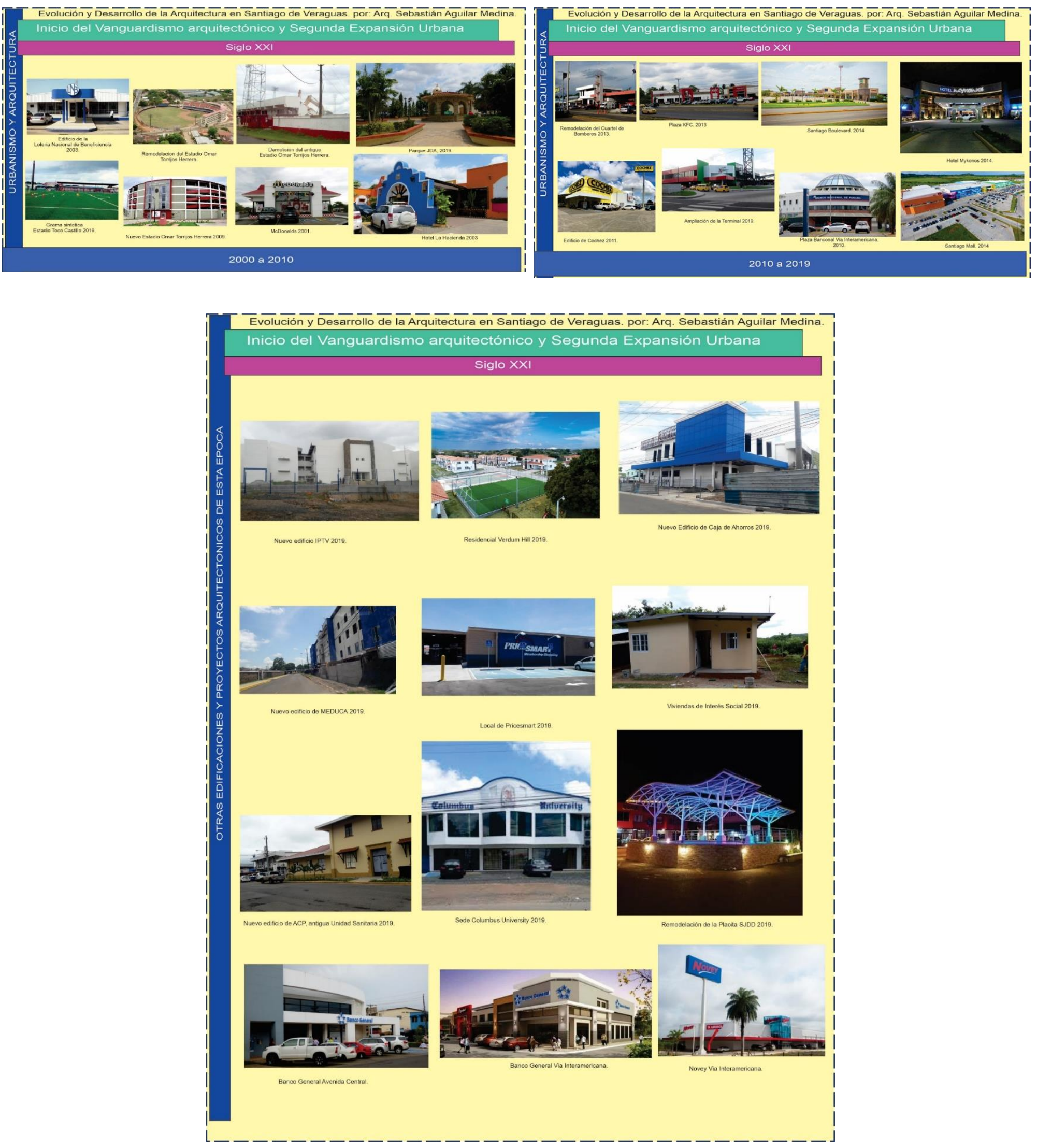